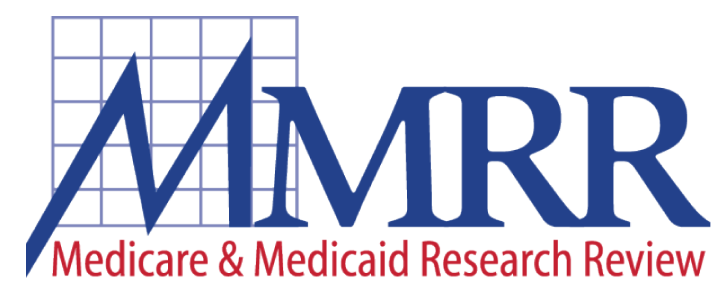

2013: Volume 3, Number 3

A publication of the Centers for Medicare \& Medicaid Services, Office of Information Products \& Data Analytics

\title{
Effect of Long-term Care Use on Medicare and Medicaid Expenditures for Dual Eligible and Non-dual Eligible Elderly Beneficiaries
}

Robert L. Kane, ${ }^{1}$ Andrea Wysocki, ${ }^{1}$ Shriram Parashuram, ${ }^{1}$ Tetyana Shippee, ${ }^{1}$ Terry Lum ${ }^{2}$ ${ }^{1}$ University of Minnesota School of Public Health

${ }^{2}$ The University of Hong Kong

Background: Dual eligible Medicare and Medicaid beneficiaries consume disproportionate shares of both programs.

Objectives: To compare Medicare and Medicaid expenditures of elderly dual eligible beneficiaries with non-dual eligible beneficiaries based on their long-term care (LTC) use.

Research Design: Secondary analysis of linked MAX and Medicare data in seven states.

Subjects: Dual eligible adults (65+) receiving LTC in institutions, in the community, or not at all; and Medicare non-dual eligibles.

Measures: Medicaid acute medical and LTC expenditures per beneficiary year, Medicare expenditures.

Results: Among dual eligibles and non-dual eligibles, the average number of diseases and case mix scores are higher for LTC users. Adjusting for case mix virtually eliminates the difference for medical costs, but not for LTC expenditures. Adjusting for LTC status reduces the difference in LTC costs, but increases the difference in medical costs.

Conclusions: Efforts to control costs for dual eligibles should target those in LTC while better coordinating medical and LTC expenditures.

Keywords: Access, Demand, Utilization of Services, Aging, Elderly, Geriatrics, Chronic Disease, Disability, Health Care Costs, Long Term Care, Home Care, Nursing Homes, Medicaid, Medicare

ISSN: 2159-0354

doi: http://dx.doi.org/10.5600/mmrr.003.03.a05 


\section{Medicare \& Medicaid Research Review} 2013: Volume 3, Number 3

\section{Mission Statement}

Medicare \& Medicaid Research Review is a peerreviewed, online journal reporting data and research that informs current and future directions of the Medicare, Medicaid, and Children's Health Insurance programs. The journal seeks to examine and evaluate health care coverage, quality and access to care for beneficiaries, and payment for health services.

\section{http://www.cms.gov/MMRR/}

\section{U.S. Department of Health \& Human Services Kathleen Sebelius Secretary}

\section{Centers for Medicare \& Medicaid Services Marilyn Tavenner Administrator}

Editor-in-Chief

David M. Bott, Ph.D.

The complete list of Editorial Staff and Editorial Board members may be found on the MMRR Web site (click link): $\underline{\text { MMRR Editorial Staff Page }}$

Contact: $\underline{\text { mmrr-editors@cms.hhs.gov }}$

Published by the Centers for Medicare \& Medicaid Services.

All material in the Medicare \& Medicaid Research

Review is in the public domain and may be duplicated without permission. Citation to source is requested.

\section{Background}

Individuals eligible and enrolled simultaneously for Medicare and Medicaid-commonly referred to as "dual eligible" or "duals"-have often been cited as accounting for a disproportionate share of Medicare and Medicaid spending compared with non-dual eligible beneficiaries. In the Medicare program, dual eligible beneficiaries account for 16 percent of enrollees, but about 25 percent of expenditures. In Medicaid, they account for 18 percent of enrollees, but about 46 percent of expenditures (Jacobson, Neuman, \& Damico, 2012; MedPAC, 2010). Despite important policy implications presented by duals, published information on this population is sparse.

Medicare-Medicaid enrollees are a heterogeneous group (Coughlin, Waidmann, \& Phadera, 2012). They include persons with developmental disabilities, young adults with acquired disability, and older persons. Ouranalysis focuses on the latter group. Some older people are eligible for Medicaid by virtue of poverty, but many spend down to become Medicaid eligible as a result of long-term care (LTC) costs. The latter Medicare-Medicaid enrollees are frailer and their case mix tends to be more severe than those of other Medicare-Medicaid enrollees (Kaiser Commission on Medicaid and the Uninsured, 2011). These Medicare-Medicaid enrollees also have more chronic conditions resulting in higher medical care costs. Among Medicare-Medicaid enrollees who use longterm care, those in nursing facilities are frailer and sicker than those living in the community. However, little attention has been given to the role of long-term care setting and case-mix in Medicare-Medicaid enrollees' medical and LTC costs. 
Higher rates of health care spending among Medicare-Medicaid enrollees have been documented (Dreyfus \& Davidson, 2012; Jacobson, Neuman, \& Damico, 2010; Kaiser Commission on Medicaid and the Uninsured, 2011, 2012; Kane, Homyak, Parashuram, Lee, \& Woodhouse, 2008; Kasper, Watts, \& Lyons, 2010; Young, Garfield, Musumeci, Clemens-Cope, Lawton, 2012). However, the data are mainly descriptive and do not account for the role of casemix or other characteristics. One explanation for disproportionate costs is that double program coverage results in overlaps and inefficiencies, leading to proposed solutions such as integrated care (Gold, Jacobson, \& Garfield, 2012; Meyer, 2012; Neuman, Lyons, Rentas, \& Rowland, 2012). There is a clear need to identify the specific characteristics of Medicare-Medicaid enrollees that account for their disproportionately high expenditures for medical and long-term care.

The only study to examine the effect of casemix on Medicare-Medicaid enrollees' higher LTC costs found that they were largely attributable to greater levels of dysfunction and disease burden (Liu, Long, \& Aragon, 1998). Our study builds upon this work with more recent data and a separate examination of the role of LTC care setting and case mix for elderly MedicaidMedicare beneficiaries. We analyzed Medicare and Medicaid data to examine how type of long-term care and case mix affect expenditures towards medical care and LTC for older MedicareMedicaid enrollees and non-duals, and how these expenditures vary between programs and settings. In response to the findings of Bubolz, Emerson, and Skinner (2012), we also looked for evidence of de facto cross-subsidization among those covered by both Medicare and Medicaid; namely, was nursing home use (covered only by Medicaid) associated with lower medical care use (covered by Medicare)?

\section{Methods}

\section{Study Population}

Our study population consists of individuals aged 65 years and older in 2005, enrolled in (1) Medicaid only, (2) Medicare only, and (3) Medicare and Medicaid simultaneously. We selected residents from seven states (Arkansas, Florida, Minnesota, New Mexico, Texas, Vermont, and Washington) who illustrate diverse management techniques across the target populations, and diverse state characteristics; e.g., demographics, size, geography, structure of county government, and policies. The LTC waiver, state plan programs, and plan variations are summarized in Appendix Exhibit A1. All of the states had an aging and disability waiver.

In order to analyze the characteristics and expenditures of duals and non-dual beneficiaries based on LTC utilization, we classified our study sample into four groups based on program enrollment and LTC use:

1. Medicaid Community LTC-Medicaid Community LTC individuals, or individuals who used Medicaid home health or personal care state plan services, were enrolled in Medicaid physically disabled/aged Home and Community-Based Services (HCBS) waivers;

2. Medicaid Institutional LTC-Medicaid Institutional LTC individuals had nursing facility stays paid for by Medicaid. Nursing home stays covered by Medicare as part of post-acute care were treated as acute care for our analytic purposes, so the Medicaid Institutional LTC group includes only stays covered by Medicaid;

3. Medicaid No LTC-Medicaid No LTC individuals were not enrolled in any Medicaid HCBS waiver and did not have any Medicaid state plan LTC use; and 
4. Medicare Only-Medicare Only non-dual individuals were enrolled only in Medicare.

We present results for these groups separately based on dual and non-dual program enrollment status.

In order to analyze expenditures for each of these LTC groups at the beneficiary year level, we excluded individuals who belonged to more than one of these LTC groups during 2005 (117,200 out of $1,230,567$, or 9.5 percent of our total sample). We excluded individuals identified as having end stage renal disease (ESRD). Although they represent a small portion of the population, their high utilization of services could skew the results. Our analysis was also limited to enrollees in fee-forservice (FFS) Medicaid and Medicare. Managedcare clients accounted for substantial numbers of HCBS clients in Minnesota, Texas, and Florida, but few nursing home residents.

\section{Data Sources}

The data were derived from a project contracted by the Centers for Medicare \& Medicaid Services (CMS) to examine the factors associated with successful efforts to "rebalance" LTC financing in order to increase options for HCBS. Sources included Medicaid Analytic eXract (MAX) and Medicare administrative and claims records for 2005.

In addition, each state provided "finder files" identifying all individuals enrolled in a physically disabled/aged Medicaid HCBS waiver or who used LTC services under a state plan in 2005. We linked these "finder files" to CMS Medicaid and Medicare claims data. We used data on all elderly Medicaid recipients in each state for this analysis.

We obtained a random sample of Medicareonly beneficiaries, age 65 and older, from the Chronic Condition Warehouse (CCW), with data based on the 2005 Medicare five-percent sample. We eliminated records for individuals also covered by Medicaid. We retained only individuals with 12 months of enrollment in Medicare Part A and Part $\mathrm{B}$, in order to distinguish between months when a beneficiary was not eligible and months in which no claim was made. Although Medicare-related post-acute care costs are included, information is unavailable for individuals privately purchasing community or institutional LTC.

To analyze the medical and LTC expenditures for beneficiaries in each LTC service group, we linked the files containing beneficiaries' LTC group classification with their Medicaid and Medicare claims in 2005. We used the Eligible Identifier Number obtained from the MAX person summary (PS) file to extract Medicaid claims from the MAX utilization files (MAX IP: inpatient, MAX LT: longterm care, MAX OT: other services), and the CMS Health Insurance Claim (HIC) number to extract Medicare claims from the MedPAR (finalized inpatient claims), and from Outpatient, Carrier, and Home Health files.

\section{Calculating Expenditures}

Our unit of analysis was beneficiary year. For each LTC service group, we calculated total Medicaid and Medicare expenditures for medical care and LTC in 2005. All Medicare payment towards inpatient acute services, outpatient ambulatory services, post-acute care services through skilled nursing facilities and home health, and other services such as durable medical equipment, were grouped under medical care. Medicaid expenditure for medical care included payment for inpatient care stays, ambulatory care, primary care case management, labs/x-rays, rehabilitation, physical therapy/occupational therapy/speech-languagepathology therapy, and hospice care. Medicaid expenditure for LTC included state plan payments towards nursing facility services, intermediate care facility services, home health services, personal 
care services, targeted case management, and transportation. We classified services, through the Medicaid Statistical Information System (MSIS) and identified as Medicaid "Other Services" on the MAX utilization files, as medical or LTC, based on the Healthcare Common Procedure Coding System (HCPCS) and local codes found on the claims. Expenditures for the following MSIS types of service were excluded: mental hospital services for the aged, dental services, sterilizations, abortions, religious non-medical healthcare institutions, and unknown. To more closely approximate current post-Medicare Prescription Drug, Improvement, and Modernization Act (MMA) conditions, we excluded Medicaid payment for prescription drugs.

\section{Regression Models}

We conducted a series of regression analyses to assess the effect of dual eligibility on expenditures. The following three dependent variables were used for the regressions: (1) total medical care expenditures per beneficiary year, (2) total LTC expenditures per beneficiary year, and (3) total expenditures (the sum of medical care and LTC) per beneficiary year. We ran four regression models with each dependent variable. The first model adjusted for state, gender, race, age, urbanity, and dual eligibility status. The second model included all of the independent variables from the first model, in addition to the Chronic Illness and Disability Payment System (CDPS) case mix score for dual and non-dual Medicaid enrollees, and a calculated CDPS-Medicare case mix score for Medicare Only enrollees. The CDPS is a diagnostic classification system that Medicaid programs use to make health-based capitated payments for TANF and disabled Medicaid beneficiaries (Kronick, Gilmer, Dreyfus, \& Lee, 2000). We calculated a beneficiary's CDPS case mix score using all diagnoses (on Medicaid/Medicare claims) in 2005 and demographic characteristics (viz., age, sex, disability, reason for Medicaid/Medicare eligibility). The third model included all of the independent variables from the first model, plus a beneficiary's LTC group (Medicaid Community LTC, Medicaid Institutional LTC, Medicaid No LTC, and Medicare Only). The fourth model added the beneficiary's CDPS case mix score to Model 3.

Because many beneficiaries ( $>20$ percent) had no expenditures for each of these dependent variables, we used a two-part model for predicting expenditures. First, we ran logistic regressions to predict the probability of a person having any of the three types of expenditures during the year. For individuals with any expenditure, we used Generalized Estimating Equations (GEE) to obtain their predicted expenditures; we used a gamma distribution with a log link, because of the skewed pattern of expenditures. We used GEE to account for the correlation between observations within LTC groups and states. Finally, we calculated the predicted expenditures for the whole study sample using the predicted probability of having an expenditure and the predicted expenditure for individuals with a positive expenditure. We performed all analyses using SAS Version 9.2.

Because the dependent variables are defined as log expenditures, which cannot be intuitively interpreted in dollar units, we calculated the predicted mean beneficiary year expenditure for the categorical variables and report these results. The predicted mean beneficiary year expenditure gives the average expenditure for a beneficiary year for each categorical group, while the other predictor variables are fixed at their mean values.

\section{Results}

Exhibit 1 shows the characteristics of our sample across the seven states. Medicare-Medicaid enrollees were on average older and more likely to 
Exhibit 1. Characteristics of Dual and Non-Dual Samples Across States

\section{Duals}

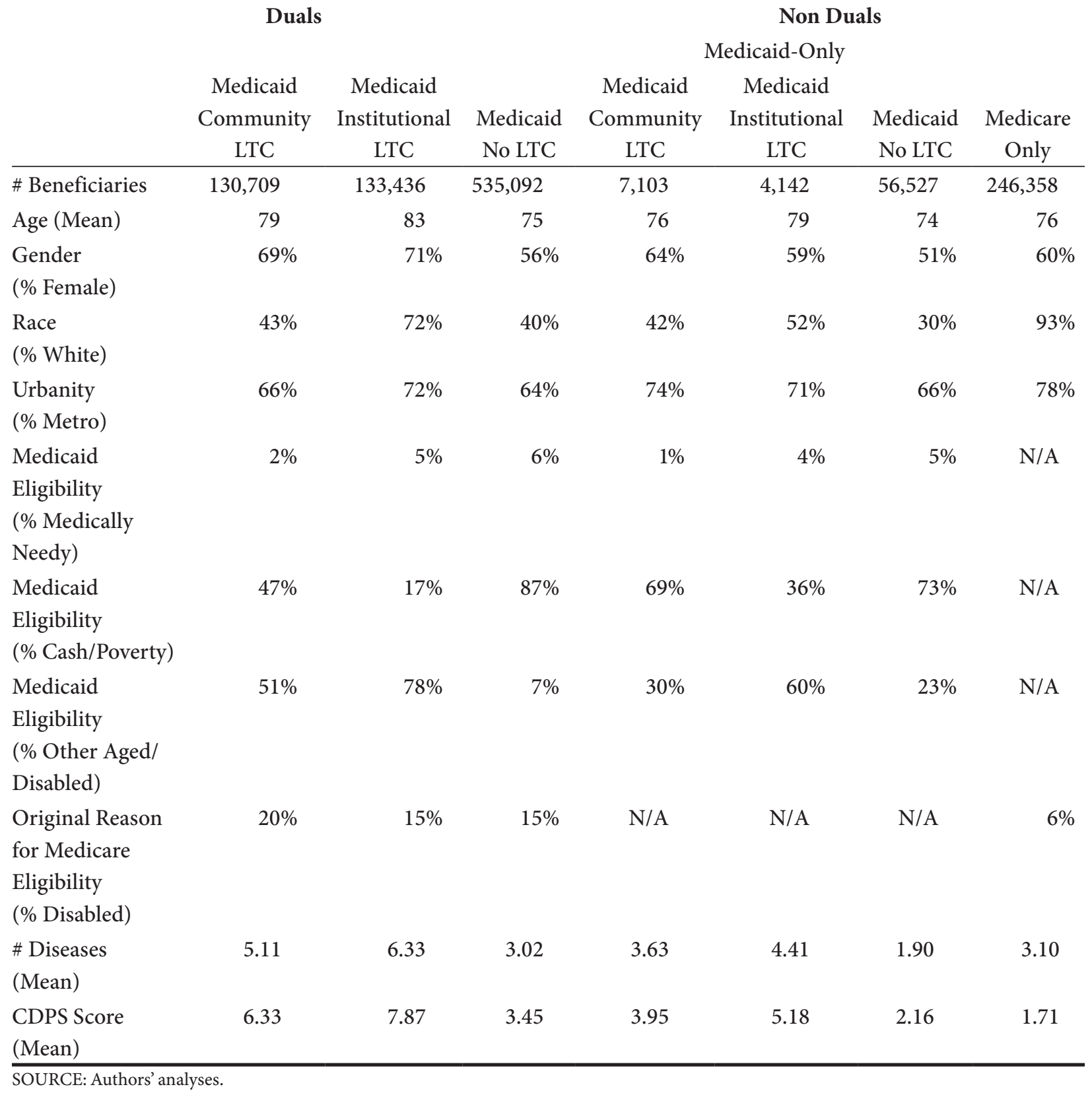

be female, White, and live in rural areas. MedicareMedicaid LTC users were more likely to be eligible for Medicaid due to medical necessity or age/ disability, while Medicare-Medicaid non-LTC users were more likely to be eligible for Medicaid due to spend down than the corresponding Medicaid only enrollees. Medicare-Medicaid enrollees were more likely to be originally eligible for Medicare due to disability than Medicare only enrollees. They had a higher average number of diseases from the following diagnostic categories: cardiovascular, cancer, cerebrovascular, dementia, developmental disability, diabetes, gastrointestinal, infectious disease, metabolic, nervous system, psychiatric, pulmonary, renal, skeletal and connective, and skin. Their average Chronic Disease and Disability Payment System (CDPS) case mix score was higher. 
Amongboth duals and non-duals, enrolleesin an LTC group had a higher average number of diseases and case mix scores than enrollees not in an LTC group. Conversely, for each LTC group, MedicareMedicaid enrollees had higher numbers of diseases and case mix scores than non-duals. However, the case mix measures for non-duals in an LTC group were higher than for Medicare-Medicaid enrollees not in an LTC group. The Medicare-only group was consistently lower than the other groups.

Exhibit 2 shows the Medicaid and Medicare medical and LTC beneficiary-year expenditures. Across the seven states, Medicare-Medicaid enrollees and non-duals in LTC groups had higher total expenditures than enrollees not in an LTC group. Medicare-Medicaid enrollees not in an LTC group had lower total expenditures than non-duals in the community and institutional LTC groups. Among the Medicare-Medicaid enrollees, the total medical expenditures were lower for those in institutions than those receiving LTC in the community, although the total expenditures were roughly comparable. Bydefinition, all expenditures for the non-LTC groups were towards medical care. Medical care expenditures were much higher for Medicare-Medicaid enrollees compared to non-duals in corresponding LTC groups. By contrast, total LTC expenditures were higher for non-duals. The Medicare-only beneficiaries had dramatically lower Medicare expenditures than duals in all LTC groups.

Exhibit 3 shows the results from a series of regressions designed to examine the relationship between dual status and three dependent variables: medical care expenditure, LTC expenditure, and the sum of these, after adjusting for different baseline characteristics. The results are expressed here as the difference in the marginal means; i.e., the average size of the effect of being a MedicareMedicaid enrollee. (The full regression models are shown in Appendix Exhibit A2.)

For each dependent variable, we performed four regressions. In model 1, we adjusted for state, age, gender, or urban/rural location. The second model

Exhibit 2. Beneficiary Year Expenditures of Dual and Non-Dual Samples Across States

\begin{tabular}{|c|c|c|c|c|c|c|c|}
\hline \multicolumn{4}{|c|}{ Duals } & \multicolumn{4}{|c|}{ Non Duals } \\
\hline & \multirow[b]{2}{*}{$\begin{array}{c}\text { Medicaid } \\
\text { Community } \\
\text { LTC }\end{array}$} & \multirow[b]{2}{*}{$\begin{array}{c}\text { Medicaid } \\
\text { Institutional } \\
\text { LTC }\end{array}$} & \multirow[b]{2}{*}{$\begin{array}{l}\text { Medicaid } \\
\text { No LTC }\end{array}$} & \multicolumn{3}{|c|}{ Medicaid-Only } & \multirow[b]{2}{*}{$\begin{array}{c}\text { Medicare } \\
\text { Only }\end{array}$} \\
\hline & & & & $\begin{array}{c}\text { Medicaid } \\
\text { Community } \\
\text { LTC }\end{array}$ & $\begin{array}{c}\text { Medicaid } \\
\text { Institutional } \\
\text { LTC }\end{array}$ & $\begin{array}{l}\text { Medicaid } \\
\text { No LTC }\end{array}$ & \\
\hline Medicaid & $\$ 974$ & $\$ 447$ & $\$ 557$ & $\$ 6,453$ & $\$ 4,993$ & $\$ 2,845$ & N/A \\
\hline \multicolumn{8}{|l|}{ Medical } \\
\hline Medicaid LTC & $\$ 8,435$ & $\$ 32,867$ & $\$ 0$ & $\$ 13,021$ & $\$ 37,126$ & $\$ 0$ & $\mathrm{~N} / \mathrm{A}$ \\
\hline Total Medicaid & $\$ 9,410$ & $\$ 33,315$ & $\$ 557$ & $\$ 19,474$ & $\$ 42,119$ & $\$ 2,844$ & N/A \\
\hline Medicare & $\$ 75,878$ & $\$ 48,810$ & $\$ 16,383$ & N/A & N/A & $\mathrm{N} / \mathrm{A}$ & $\$ 5,892$ \\
\hline \multicolumn{8}{|l|}{ Medical } \\
\hline Medicare LTC & $\$ 0$ & $\$ 0$ & $\$ 0$ & N/A & N/A & N/A & $\$ 0$ \\
\hline Total Medicare & $\$ 75,878$ & $\$ 48,810$ & $\$ 16,383$ & $\mathrm{~N} / \mathrm{A}$ & $\mathrm{N} / \mathrm{A}$ & $\mathrm{N} / \mathrm{A}$ & $\$ 5,892$ \\
\hline Total Medical & $\$ 76,852$ & $\$ 49,257$ & $\$ 16,940$ & $\$ 6,453$ & $\$ 4,993$ & $\$ 2,676$ & $\$ 5,892$ \\
\hline Total LTC & $\$ 8,435$ & $\$ 32,867$ & $\$ 0$ & $\$ 13,021$ & $\$ 37,126$ & $\$ 0$ & $\$ 0$ \\
\hline $\begin{array}{l}\text { Total Medical \& } \\
\text { LTC }\end{array}$ & $\$ 85,287$ & $\$ 82,124$ & $\$ 16,940$ & $\$ 19,474$ & $\$ 42,119$ & $\$ 2,844$ & $\$ 5,892$ \\
\hline
\end{tabular}


Exhibit 3. Regression Results for Expenditures

\begin{tabular}{|c|c|c|c|c|c|c|c|}
\hline \multirow[b]{2}{*}{$\begin{array}{l}\text { Model Adjusted } \\
\text { for: }\end{array}$} & & \multicolumn{2}{|c|}{$\begin{array}{l}\text { Total Medical Care } \\
\text { Expenditure per } \\
\text { Beneficiary Year }\end{array}$} & \multicolumn{2}{|c|}{$\begin{array}{c}\text { Total LTC } \\
\text { Expenditure per } \\
\text { Beneficiary Year }\end{array}$} & \multicolumn{2}{|c|}{$\begin{array}{l}\text { Total Expenditure per } \\
\text { Beneficiary Year }\end{array}$} \\
\hline & & $\begin{array}{l}\text { Marginal } \\
\text { Mean } \\
\text { Medical } \\
\text { Care \$ }\end{array}$ & $\begin{array}{c}\text { Diff. in } \\
\text { Marginal } \\
\text { Mean Medical } \\
\text { Care \$ }\end{array}$ & $\begin{array}{l}\text { Marginal } \\
\text { Mean } \\
\text { LTC \$ }\end{array}$ & $\begin{array}{l}\text { Diff. in } \\
\text { Marginal } \\
\text { Mean } \\
\text { LTC \$ }\end{array}$ & $\begin{array}{l}\text { Diff. in } \\
\text { Marginal } \\
\text { Mean } \\
\text { Total \$ }\end{array}$ & $\begin{array}{c}\text { Diff. in } \\
\text { Marginal } \\
\text { Mean } \\
\text { Total \$ }\end{array}$ \\
\hline State, Gender, & Dual & $\$ 21,237$ & & $\$ 17,849$ & & $\$ 26,124$ & \\
\hline $\begin{array}{l}\text { Race, Age, } \\
\text { Urbanity, Dual } \\
\text { Eligibility }\end{array}$ & Non-Dual & $\$ 6,642$ & $\$ 14,595$ & $\$ 17,739$ & $\$ 110^{* *}$ & $\$ 7,056$ & $\$ 19,068$ \\
\hline + Case Mix Score & $\begin{array}{c}\text { Dual } \\
\text { Non-Dual }\end{array}$ & $\begin{array}{r}\$ 13,703 \\
\$ 9,202\end{array}$ & $\$ 4,501$ & $\begin{array}{l}\$ 18,068 \\
\$ 18,663\end{array}$ & $(\$ 595)^{*}$ & $\begin{array}{r}\$ 18,130 \\
\$ 9,240\end{array}$ & $\$ 8,890$ \\
\hline + LTC group & $\begin{array}{c}\text { Dual } \\
\text { Non-Dual }\end{array}$ & $\begin{array}{l}\$ 26,334 \\
\$ 11,051\end{array}$ & $\$ 15,283$ & $\begin{array}{l}\$ 14,846 \\
\$ 16,295\end{array}$ & $(\$ 1,449)$ & $\begin{array}{l}\$ 31,210 \\
\$ 14,126\end{array}$ & $\$ 17,084$ \\
\hline $\begin{array}{l}\text { + Case Mix Score } \\
\text { + LTC Group }\end{array}$ & Dual & $\$ 18,598$ & $\$ 10,199$ & $\$ 14,892$ & $(\$ 1,588)$ & $\$ 23,832$ & $\$ 11,438$ \\
\hline & Non-Dual & $\$ 8,399$ & & $\$ 16,480$ & & $\$ 12,394$ & \\
\hline
\end{tabular}

included all variables from model 1 , in addition to the beneficiary's case mix score. In model 3, we included the variables from model 1 and the beneficiary's LTC status. The fourth regression adjusted for all of the variables. Medicare-Medicaid enrollee status is consistently associated with higher medical care and total expenditures even after the adjustments. Being non-dual was associated with higher long-term care expenditures after adjustment for case mix and/or LTC group. The size of the estimate (the standardized coefficient) and the corresponding difference in the mean marginal cost are generally reduced as more adjustments are made, but the patterns differ somewhat across dependent variables. Adjusting for case mix lowers the difference for medical expenditures and increases the difference for LTC expenditures between dual and non-dual enrollees. However, adjusting for LTC increases the difference in both medical expenditures and LTC expenditures. The effect of case mix adjustment on expenditures is attenuated after adjusting for LTC status.
Marginal mean predicted expenditures for medical and LTC by type of LTC and dual status are shown in Exhibit 4; the last column shows the expenditures for individuals enrolled only in Medicare. Most striking is that LTC status affects expenditures more than dual status. For medical care, those getting LTC in the community have the highest expenditures. The medical expenditures of Medicare-Medicaid enrollees are almost twice as high as those for non-duals across all LTC and nonLTC groups. LTC expenditures for non-duals in institutions and community are higher than those for Medicare-Medicaid enrollees. Non-LTC users who were Medicare-Medicaid enrollees have the highest medical care expenditures. But Medicaid non-duals who used LTC had higher medical care expenditures than Medicare-Medicaid non-LTC users.

Medicaid expenditures for MedicareMedicaid enrollees are said to be shaped by Medicare's omissions. However, the generosity of state Medicaid programs can affect Medicare spending. Exhibit 5 examines the mean state 
Exhibit 4. Marginal Mean Predicted Medical Care and LTC Expenditure per Beneficiary Year for Duals and Nonduals by Type of LTC

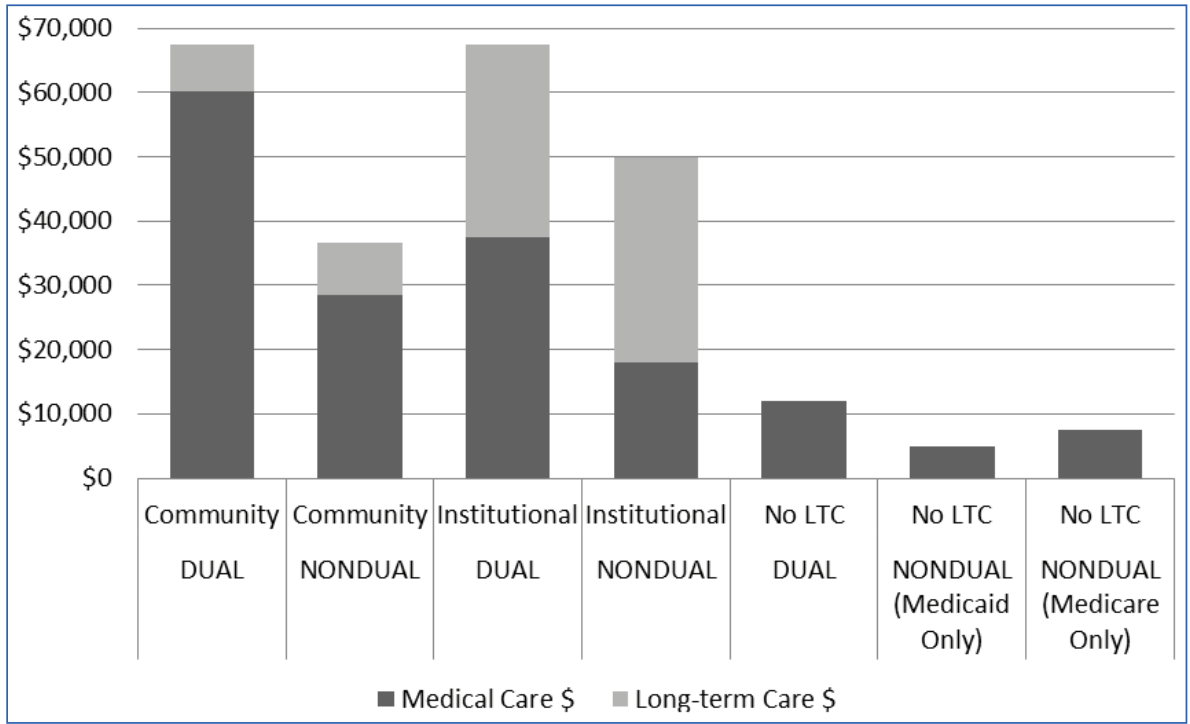

SOURCE: Authors' analyses.

Exhibit 5. Mean Medicaid and Medicare Expenditures by State for Duals in 2005

\begin{tabular}{lccc}
\hline State & $\begin{array}{c}\text { Mean Medicaid } \\
\text { Expenditures }\end{array}$ & $\begin{array}{c}\text { Mean Medicare } \\
\text { Expenditures }\end{array}$ & Medicare/Medicaid Ratio \\
\hline Vermont & $\$ 40,324$ & Community LTC Recipients & 4.06 \\
New Mexico & $\$ 163,767$ & 3.05 \\
Minnesota & $\$ 27,756$ & $\$ 84,718$ & 4.26 \\
Florida & $\$ 16,374$ & $\$ 69,813$ & 25.96 \\
Washington & $\$ 11,129$ & $\$ 288,899$ & 4.20 \\
Arkansas & $\$ 10,546$ & $\$ 44,283$ & 11.06 \\
Texas & $\$ 8,441$ & $\$ 93,320$ & 5.59 \\
& $\$ 7,781$ & $\$ 43,459$ & 0.73 \\
Vermont & & Institutional LTC Recipients & 0.85 \\
New Mexico & $\$ 59,531$ & 1.24 \\
Florida & $\$ 81,166$ & $\$ 41,069$ & 0.93 \\
Washington & $\$ 48,476$ & $\$ 53,202$ & 2.06 \\
Arkansas & $\$ 42,786$ & $\$ 35,369$ & 1.84 \\
Texas & $\$ 37,991$ & $\$ 48,512$ & 0.73 \\
Minnesota & $\$ 26,521$ & $\$ 38,117$ & \\
& $\$ 26,175$ & $\$ 24,306$ & 17.52 \\
Arkansas & $\$ 19,914$ & $\$ 26,822$ & 21.34 \\
New Mexico & & $\$ 24,544$ & 20.42 \\
Vermont & $\$ 1,387$ & Non-LTC Recipients & \\
\hline
\end{tabular}


Exhibit 5 Continued. Mean Medicaid and Medicare Expenditures by State for Duals in 2005

\begin{tabular}{lrrr}
\hline Washington & $\$ 606$ & $\$ 12,742$ & 21.03 \\
Texas & $\$ 534$ & $\$ 8,394$ & 15.72 \\
Florida & $\$ 401$ & $\$ 20,996$ & 52.36 \\
Minnesota & $\$ 259$ & $\$ 15,375$ & 59.36 \\
\hline
\end{tabular}

SOURCE: Authors' analyses.

Medicare expenditure per beneficiary year for different types of Medicare-Medicaid enrollees; the ratio of Medicaid to Medicare payment per beneficiary per year is also displayed. The pattern across states varies widely. For example, Florida has modest Medicaid expenditures for the elderly community LTC recipients and very high Medicare expenditures, but its pattern for institutional elderly LTC recipients is much more balanced. The ratio of Medicare to Medicaid expenditure is very high for those Medicare-Medicaid enrollees not receiving any LTC. The rank order of states for each type of expenditure was generally consistent, using both raw and adjusted analyses (see Appendix Exhibit A3).

\section{Discussion and Implications}

This study examines the effect of case-mix and care setting on medical and LTC expenditures for dual Medicare-Medicaid beneficiaries. Our results suggest that much of the higher cost of health care attributed to dual status may be due to their higher disease burden and/or associated LTC use. However LTC use and frailty are more important than duality with respect to higher medical care expenditures. Medicaid only non-duals who used LTC had higher predicted medical care expenditures than MedicaidMedicare beneficiaries who did not use LTC.

Paying attention to subgroups based on LTC status may provide helpful insights. It is important to tease apart factors that influence expenditures. Not surprisingly, LTC use is associated with higher Medicaid expenditures, and multiple chronic diseases with higher Medicare expenditures. Medicare-Medicaid enrollees who do not receive LTC have substantially lower Medicare and Medicaid expenditures than those who do, but have higher Medicare expenditures than Medicareonly beneficiaries. Adjusting for case mix scores substantially diminishes the differences in dual and non-dual expenditures for medical care, but not for LTC. Adjusting for LTC use reduces the differences between duals and non-duals for total expenditures, but increases the difference between medical and LTC expenditures, in opposite directions: medical expenditures are higher, but LTC costs are lower.

Among LTC users who are also MedicareMedicaid enrollees the medical expenditures are higher for those in the community compared to nursing home residents. Although Bubolz, Emerson, and Skinner's analyses have suggested cost shifting from Medicaid to Medicare for care of Medicare-Medicaid enrollees (Bubolz, Emerson, \& Skinner, 2012), we note the opposite effect. Our findings suggest that nursing homes may be subsidizing Medicare by reducing hospital use and lowering medical expenditures. The difference is not likely due to case mix, which is higher in nursing homes than in community LTC. The mechanism for the savings is not clear. Presumably some cases are treated in the nursing home that would otherwise have been sent to a hospital. This difference in management may reflect better medical (or nursing) care or it may result from a different belief about the value of hospital care for nursing home residents. 
Our findings have policy implications. Although the case mix effects of Medicare-Medicaid enrollees has been noted for some time (Liu et al., 1998), it remains a persistent policy challenge. Because the higher expenditures of duals come from distinct factors, no single solution will fully address them. Some Medicare-Medicaid enrollees would likely benefit from more intensive chronic disease management (Kane, Priester, \& Totten, 2005), while those receiving LTC need both more efficient care and better coordination between LTC and medical care. Some view managed care as a solution, but its public savings depend on how well the rates are set (Gross, Temkin-Greener, Kunitz, \& Mukamel, 2004; Kane, Homyak, Bershadsky, \& Flood, 2006; Kane, Homyak, Bershadsky, Flood, \& Zhang, 2004; Kane, Weiner, Homyak, \& Bershadsky, 2001). The basic rate setting for Medicare Advantage uses nursing home residence as a risk factor, but for Medicare-Medicaid enrollees this effect may be exaggerated. The basis for the difference in medical care use for LTC recipients in the community and in nursing homes deserves careful attention. If nursing homes are cross-subsidizing Medicare, a combined capitation rate may address this by allowing the managed care entity to decide how to address this subsidy.

The results of these analyses imply that efforts to address cost controls in duals should recognize the importance of targeting LTC users and improving the coordination of medical care and LTC. Finding effective ways to address chronic illness has proven challenging (Boult et al., 2011; Kane, 2009).

LTC has been recognized as a cost driver (or as an indicator of individuals with high Medicare expenditures). Nursing home residents account for a disproportionate amount of Medicare expenditures, linked to heavy hospital use (Jacobson et al., 2010). This offers a tempting target for efforts to reduce that utilization. Some enthusiasm has been generated about the potential for introducing better primary care for nursing home residents and thereby saving money for Medicare (Grabowski, O’Malley, \& Barhydt, 2007; Ouslander et al., 2010; Saliba et al., 2000; Sylvia et al., 2008), but so far few such efforts have been effective (Peikes, Chen, Schore, \& Brown, 2009). One successful model was developed by Evercare, a Medicare Advantage institutional Special Needs Program; it used aggressive care from nurse practitioners to treat nursing home residents in the nursing home and paid the nursing homes for agreeing to retain such patients (Kane, Keckhafer, Flood, Bershadsky, \& Siadaty, 2003).

Our study has several limitations. It reflects the findings from only seven states and cannot be automatically extrapolated to the entire country. Managed care enrollees are excluded. In Minnesota, a large proportion of elderly Medicare-Medicaid eligible people are enrolled in Minnesota Senior Health Options (MSHO), a special program for duals. Other states also enroll beneficiaries in managed care programs, such as the Nursing Home Diversion program in Florida and the STAR Plus program in Texas. We have no data on the composition of the managed care enrollees in relation to those in feefor-service. Although we did adjust for state effects, we could not adjust for small area variations and local market effects (Fisher et al., 2003a, 2003b).

Nonetheless, this study highlights important issues that must be confronted by programs that address Medicare-Medicaid enrollees. We need programs to integrate medical and long-term care; managed care may offer one vehicle to accomplish this goal. As more states turn to managed care as a way to deal with this group of disproportionately high users, we will need careful attention to informed rate setting.

\section{Disclaimer}

This work is solely that of the authors and does not represent any policies or opinions of the Centers for Medicare \& Medicaid Services. 


\section{Correspondence}

Robert L. Kane, M.D., University of Minnesota School of Public Health, 420 Delaware St. SE, D351 Mayo (MMC 197), Minneapolis, MN 55455, kanex001@umn.edu Tel. (612) 624-1185, Fax. (612) 624-8448.

\section{Acknowledgment}

The authors would like to thank William Clark and Pauline Karikari-Martin for their guidance and comments.

\section{Financial Disclosure}

This work was supported by the Centers for Medicare \& Medicaid Services Contract No. MRAD HHSM500-2005-000271 Task Order \#1 “Monitoring Chronic Disease Care and Outcomes Among Elderly: Extending the Use of MAX to Examine Rebalancing."

\section{References}

Boult, C., Reider, L., Leff, B., Frick, K. D., Boyd, C. M., Wolff, J. M., . . . Scharfstein, D. O. (2011). The effect of guided care teams on the use of health services: results from a clusterrandomized controlled trial. Archives of Internal Medicine, 171(5), 460-466. PubMed http:// dx.doi.org/10.1001/archinternmed.2010.540

Bubolz, T., Emerson, C., \& Skinner, J. (2012). State spending on dual eligibles under age 65 shows variations, evidence of cost shifting from Medicaid to Medicare. Health Affairs (Project Hope), 31(5), 939-947. PubMed http://dx.doi. org/10.1377/hlthaff.2011.0921

Coughlin, T. A., Waidmann, T. A., \& Phadera, L. (2012). Among dual eligibles, identifying the highest-cost individuals could help in crafting more targeted and effective responses. Health Affairs (Project Hope), 31(5), 10831091. PubMed http://dx.doi.org/10.1377/ hlthaff.2011.0729

Dreyfus, T. \& Davidson, E. B. (2012). Risk adjustment for dual eligibles: Breaking new ground in Massachusetts. Retrieved from http:// www.massmedicaid.org/sites/default/files/ RiskAdjustment_Jan2012_v7.pdf

Fisher, E. S., Wennberg, D. E., Stukel, T. A., Gottlieb, D. J., Lucas, F. L., \& Pinder, E. L. (2003a). The implications of regional variations in Medicare spending. Part 1: The content, quality, and accessibility of care. Annals of Internal Medicine, 138(4), 273-287. PubMed http://dx.doi. org/10.7326/0003-4819-138-4-200302180-00006

Fisher, E. S., Wennberg, D. E., Stukel, T. A., Gottlieb, D. J., Lucas, F. L., \& Pinder, E. L. (2003b). The implications of regional variations in Medicare spending. Part 2: Health outcomes and satisfaction with care. Annals of Internal Medicine, 138(4), 288-298. PubMed http://dx.doi. org/10.7326/0003-4819-138-4-200302180-00007

Gold, M. R., Jacobson, G. A., \& Garfield, R. L. (2012). There is little experience and limited data to support policy making on integrated care for dual eligibles. Health Affairs (Project Hope), 31(6), 1176-1185. PubMed http://dx.doi. org $/ 10.1377 /$ hlthaff.2012.0162

Grabowski, D. C., O’Malley, A. J., \& Barhydt, N. R. (2007). The costs and potential savings associated with nursing home hospitalizations. Health Affairs (Project Hope), 26(6), 1753-1761. PubMed http://dx.doi.org/10.1377/hlthaff.26.6.1753

Gross, D. L., Temkin-Greener, H., Kunitz, S., \& Mukamel, D. B. (2004). The growing pains of integrated health care for the elderly: Lessons from the expansion of PACE. The Milbank Quarterly, 82(2), 257-282. PubMed http:// dx.doi.org/10.1111/j.0887-378X.2004.00310.x

Jacobson, G., Neuman, T., \& Damico, A. (2010). Medicare Spending and Use of Medical Services for Beneficiaries in Nursing Homes and Other Long-Term Care Facilities: A Potential for 
Achieving Medicare Savings and Improving the Quality of Care. The Henry J. Kaiser Family Foundation.

Jacobson, G., Neuman, T., \& Damico, A. (2012). Medicare's role for dual eligible beneficiaries. Retrieved from http://www.kff.org/medicare/ upload/8138-02.pdf

Kaiser Commission on Medicaid and the Uninsured (2011). Dual Eligibles: Medicaid's Role for Low-Income Medicare Beneficiaries Retrieved 1/29/2012, from http://www.kff.org/ medicaid/upload/4091-04\%20Final(v2).pdf

Kaiser Commission on Medicaid and the Uninsured (2012). The diversity of dual eligible beneficiaries: An examination of services and spending for people eligible for both Medicaid and Medicare. (Publication \#7895-03). Retrieved from http://www.kff.org/medicaid/ upload/7895-02.pdf

Kane, R. L. (2009). What can improve chronic disease care? Journal of the American Geriatrics Society, 57(12), 2338-2345. PubMed http:// dx.doi.org/10.1111/j.1532-5415.2009.02569.x

Kane, R. L., Homyak, P., Bershadsky, B., \& Flood, S. (2006). Variations on a theme called PACE. The Journals of Gerontology. Series A, Biological Sciences and Medical Sciences, 61(7), 689-693. PubMed http://dx.doi.org/10.1093/gerona/61.7.689

Kane, R. L., Homyak, P., Bershadsky, B., Flood, S., \& Zhang, H. (2004). Patterns of utilization for the Minnesota senior options program. Journal of the American Geriatrics Society, 52, 20392044. PubMed http://dx.doi.org/10.1111/j.15325415.2004.52558.x

Kane, R. L., Homyak, P., Parashuram, S., Lee, J., \&Woodhouse, W.M. (2008). Chartbook Number 5. Analysis of the Effect of Case Mix Adjustment on Medicaid Expenditure Data for 2002 (5th in a series of 6 quantitative reports). Retrieved from http://www.hpm.umn.edu/ltcresourcecenter/ research/rebalancing/attachments/chartbooks/ Chartbook_5_Case_Mix_Adjustment_of_ Medicaid_Expenditure_Data.pdf

Kane, R. L., Keckhafer, G., Flood, S., Bershadsky, B., \& Siadaty, M. S. (2003). The effect of Evercare on hospital use. Journal of the American Geriatrics Society, 51(10), 1427-1434. PubMed http:// dx.doi.org/10.1046/j.1532-5415.2003.51461.x

Kane, R. L., Priester, R., \& Totten, A. M. (2005). Meeting the Challenge of Chronic Illness. Baltimore: Johns Hopkins University Press.

Kane, R. L., Weiner, A., Homyak, P., \& Bershadsky, B. (2001). The Minnesota Senior Health Options program: An early effort at integrating care for the dually eligible. The Journals of Gerontology. Series A, Biological Sciences and Medical Sciences, 56(9), M559-M566. PubMed http://dx.doi. org/10.1093/gerona/56.9.M559

Kasper, J., Watts, M. O., \& Lyons, B. (2010). Chronic disease and co-morbidity among dual eligibles: Implications for patterns of Medicaid and Medicare service use and spending. Retrieved from the Kaiser Family Foundation Web site: http://www.kff.org/medicaid/upload/8081.pdf

Kronick, R., Gilmer, T., Dreyfus, T., \& Lee, L. (2000). Improving health-based payment for Medicaid beneficiaries: CDPS. Health Care Financing Review, 21(3), 29-64. PubMed

Liu, K., Long, S. K., \& Aragon, C. (1998). Does health status explain higher Medicare costs of Medicaid enrollees? Health Care Financing Review, 20(2), 39-54.

MedPAC (2010). Report to the Congress, Chapter 5, "Coordinating the care of dual eligible 
beneficiaries". Washington, DC: Medicare Payment Advisory Commission. Aligning Incentives in Medicare.

Meyer, H. (2012). The coming experiments in integrating and coordinating care for 'dual eligibles'. Health Affairs (Project Hope), 31(6), 1151-1155. PubMed http://dx.doi.org/10.1377/ hlthaff.2012.0505

Neuman, P., Lyons, B., Rentas, J., \& Rowland, D. (2012). Dx for a careful approach to moving dual-eligible beneficiaries into managed care plans. Health Affairs (Project Hope), 31(6), 1186-1194. PubMed http://dx.doi.org/10.1377/ hlthaff.2012.0160

Ouslander, J. G., Lamb, G., Perloe, M., Given, J. H., Kluge, L., Rutland, T., . . S Saliba, D. (2010). Potentially avoidable hospitalizations of nursing home residents: frequency, causes, and costs [see editorial comments by Drs. Jean F. Wyman and William R. Hazzard, pp 760-761]. Journal of the American Geriatrics Society, 58(4), 627635. PubMed http://dx.doi.org/10.1111/j.15325415.2010.02768.x

Peikes, D., Chen, A., Schore, J., \& Brown, R. (2009).
Effects of care coordination on hospitalization, quality of care, and health care expenditures among Medicare beneficiaries: 15 randomized trials. Journal of the American Medical Association, 301(6), 603-618. PubMed http:// dx.doi.org/10.1001/jama.2009.126

Saliba, D., Kington, R., Buchanan, J. L., Bell, R. M., Wang, M., Lee, M. L., . . Rubenstein, L. V. (2000). Appropriateness of the decision to transfer nursing facility residents to the hospital. Journal of the American Geriatrics Society, 48(2), 154-163. PubMed

Sylvia, M.L., Griswold, M., Dunbar, L., Boyd, C. M., Park, M., \& Boult, C. (2008). Guided care: cost and utilization outcomes in a pilot study. Disease Management, 11(1), 29-36. PubMed http://dx.doi.org/10.1089/dis.2008.111723

Young, K., Garfield, R., Musumeci, M., ClemensCope, L., \& Lawton, E. (2012) Medicaid's Role for Dual Eligible Beneficiaries. Kaiser Commisiion on Medicaid and the Uninsured: Washington, DC. Retrieved from the Kaiser Family Foundation Web site: http://www.kff. org/medicaid/upload/7846-02.pdf 


\section{Appendix A}

Exhibit A1. Summary of Waiver and State Plan Analytic Groups in 2005 for Cross-state Comparison

\begin{tabular}{|c|c|c|c|c|c|c|}
\hline \multirow[b]{3}{*}{ State } & \multicolumn{2}{|c|}{ Waiver Groups } & \multicolumn{4}{|c|}{ State Plan Groups } \\
\hline & Intellectual/Developmental & & Nursing & Intermediate & Home & Personal \\
\hline & Disability & Aging \& Disability & Facility & Care Facility & Health & Care \\
\hline \multirow[t]{2}{*}{ Arkansas } & Alternative Community & - Elderly Choice & Yes & Yes & Yes & Yes \\
\hline & Services Waiver & Waiver & & & & \\
\hline \multirow[t]{2}{*}{ Florida } & Developmental Disability & - Aging and Disabled & Yes & Yes & - & - \\
\hline & Waiver & Adults Waiver- Aging & & & & \\
\hline \multirow[t]{3}{*}{ Minnesota } & Mental Retardation/ & • Elderly Waiver & Yes & - & Yes & Yes \\
\hline & Related Conditions & & & & & \\
\hline & Waiver & & & & & \\
\hline \multirow[t]{2}{*}{ New Mexico } & Developmental Disability & - Disabled and Elderly & Yes & Yes & Yes & Yes \\
\hline & Waiver & Waiver & & & & \\
\hline \multirow[t]{7}{*}{ Texas } & - Home and Community- & - Community-Based & Yes & Yes & - & Yes \\
\hline & Based Services Waiver & Alternatives Waiver & & & & \\
\hline & - Community Living & & & & & \\
\hline & Assistance and Support & & & & & \\
\hline & Services Waiver & & & & & \\
\hline & - Texas Home Living & & & & & \\
\hline & Waiver & & & & & \\
\hline \multirow[t]{2}{*}{ Vermont } & Developmental Services & - Enhanced Residential & Yes & Yes & Yes & - \\
\hline & Waiver & Care Waiver & & & & \\
\hline \multirow[t]{7}{*}{ Washington } & - Basic Wavier & - Community Options & Yes & Yes & Yes & Yes \\
\hline & - Basic Plus Waiver & Program Entry & & & & \\
\hline & - Core Waiver & System & & & & \\
\hline & - Community Protection & - Medically Needy in & & & & \\
\hline & Waiver & Home Waiver & & & & \\
\hline & & • Medically Needy- & & & & \\
\hline & & Residential Waiver & & & & \\
\hline
\end{tabular}




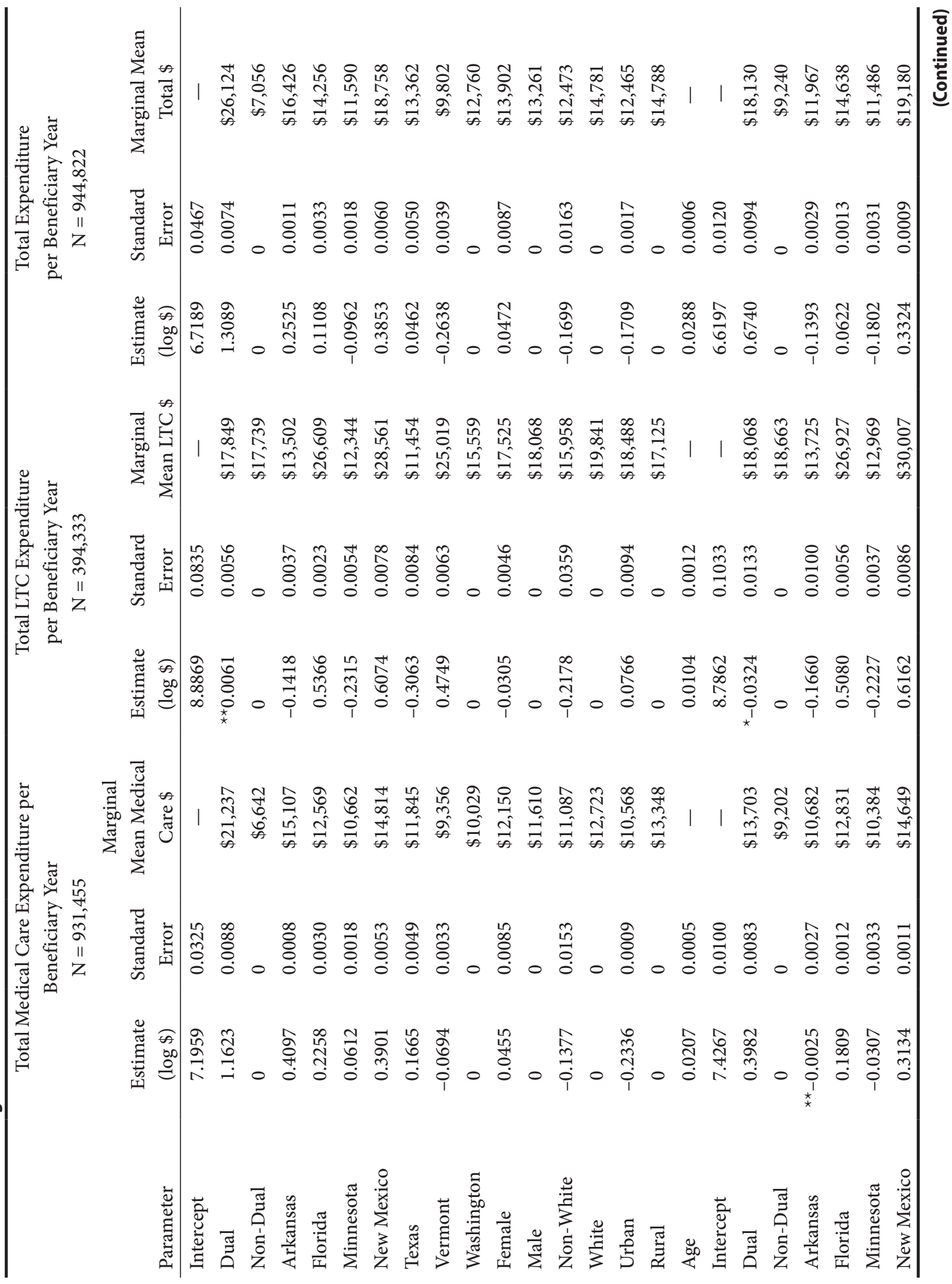




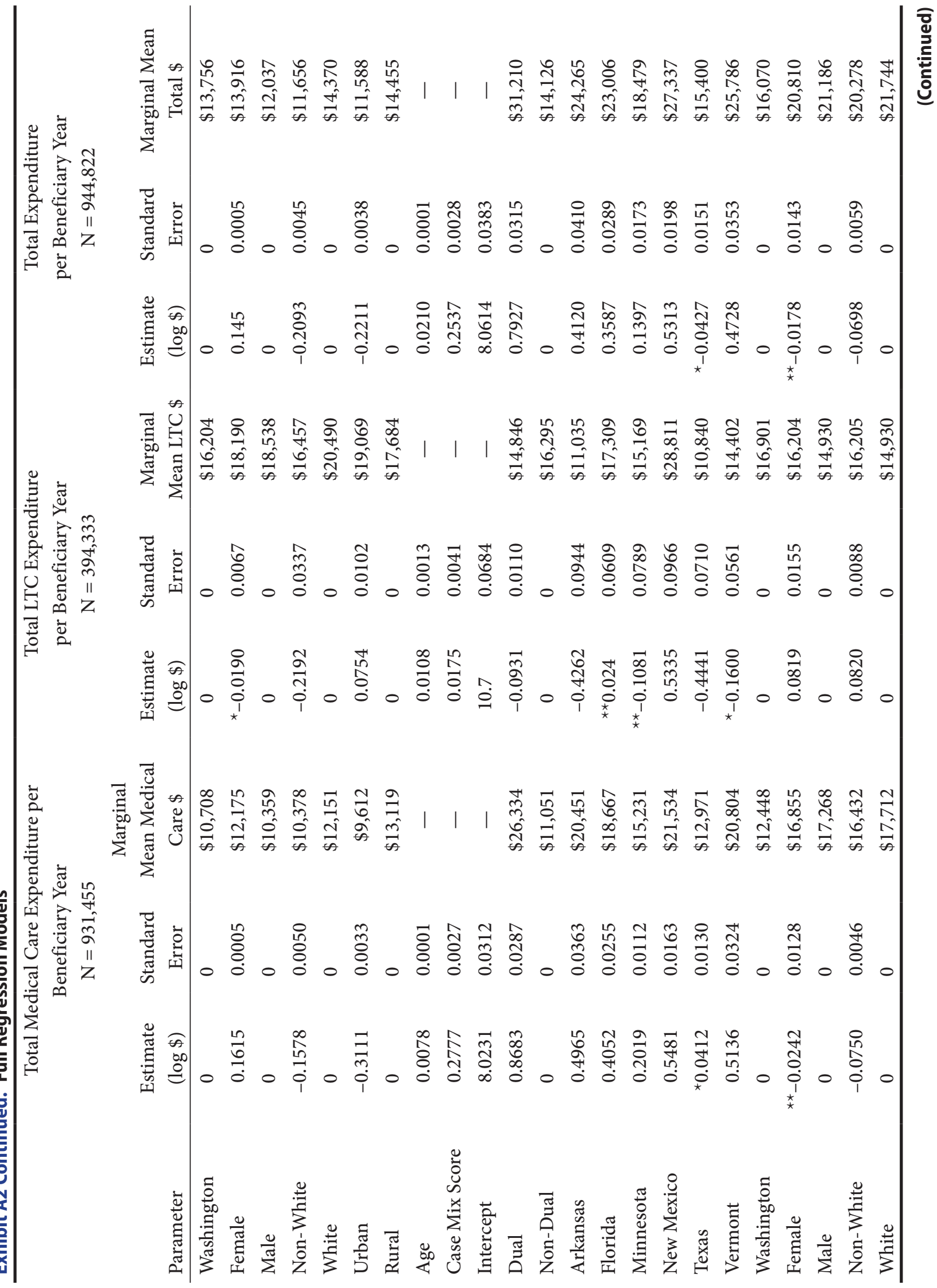




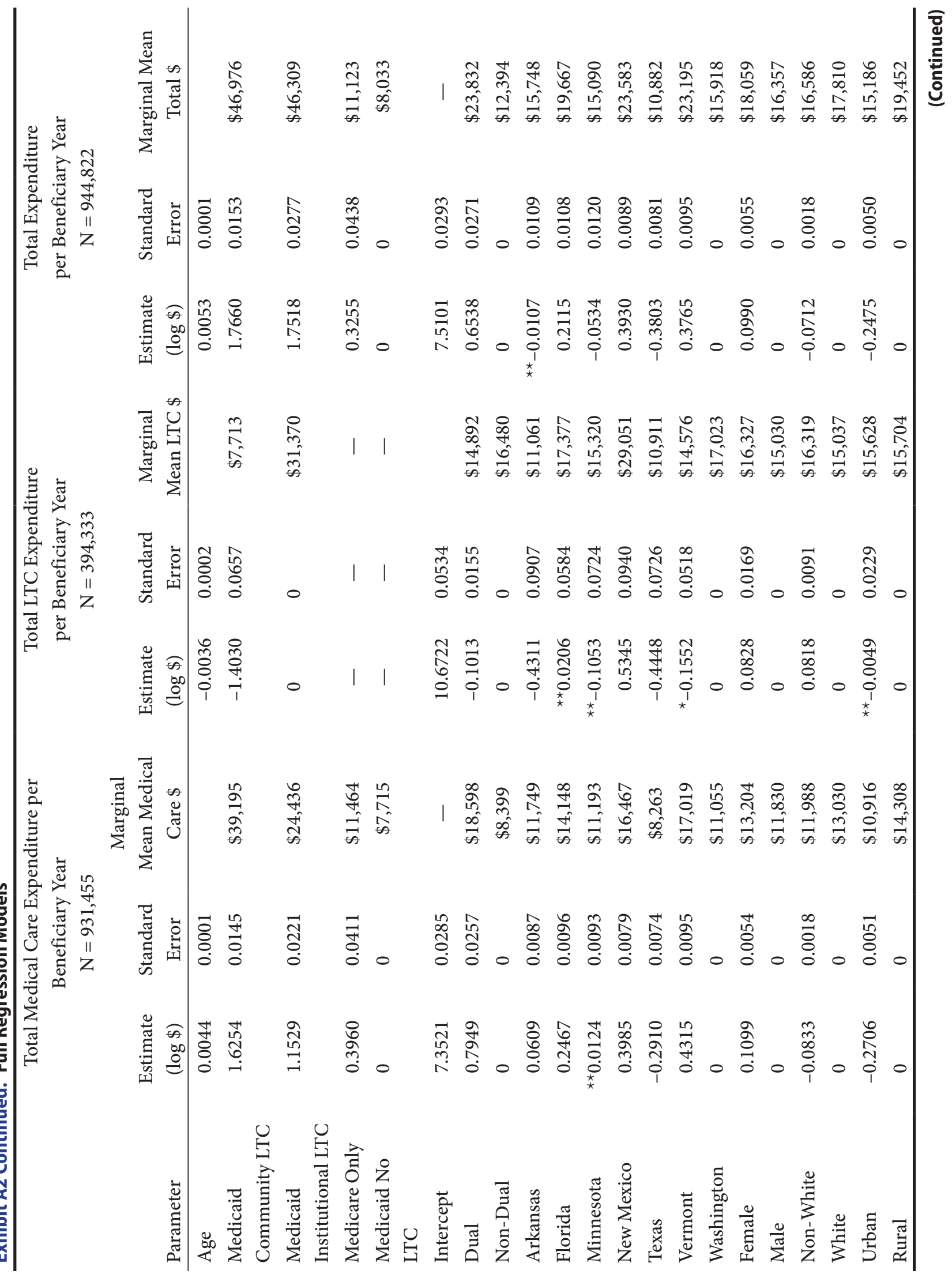




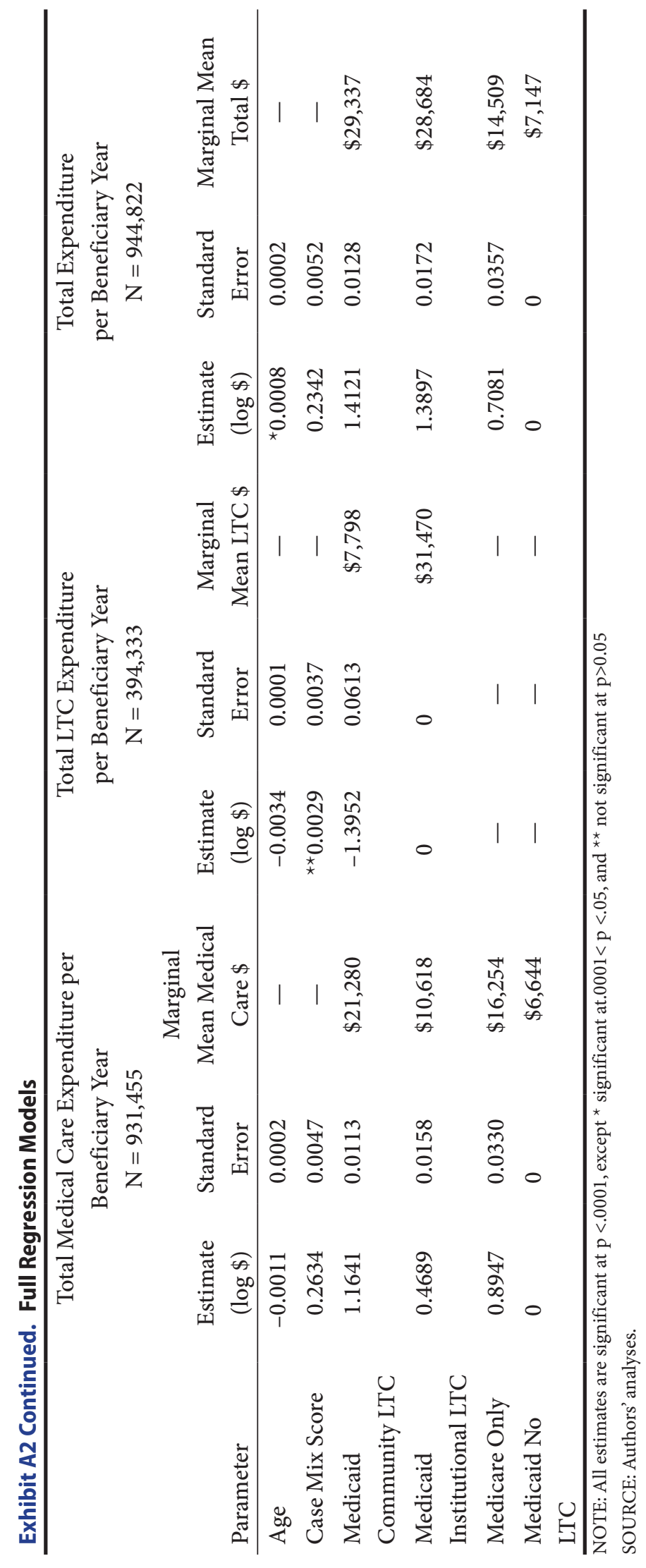

Kane, R. L., Wysocki, A., Parashuram, S., et al. 
Exhibit A3. Rank Order of Mean Medicaid Expenditures

\begin{tabular}{llllll}
\hline \multicolumn{2}{c}{ Medicaid Community LTC } & \multicolumn{2}{c}{ Medicaid Institutional LTC } & \multicolumn{2}{c}{ Medicaid No LTC } \\
Unadjusted & Adjusted & Unadjusted & Adjusted & Unadjusted & Adjusted \\
\hline Vermont & Vermont & Vermont & Vermont & Arkansas & New Mexico \\
New Mexico & New Mexico & New Mexico & New Mexico & New Mexico & Vermont \\
Minnesota & Minnesota & Florida & Washington & Vermont & Arkansas \\
Florida & Washington & Washington & Florida & Washington & Washington \\
Washington & Florida & Arkansas & Minnesota & Texas & Texas \\
Arkansas & Arkansas & Texas & Arkansas & Florida & Florida \\
Texas & Texas & Minnesota & Texas & Minnesota & Minnesota \\
\hline
\end{tabular}

SOURCE: Authors' analyses. 